\title{
Environment sustainability practices in bangladeshi cement industries
}

\section{DOI : 10.36909/jer.ICETET.14995}

Md Zahid Hasan Sabuz*, Muhammad Faizal, Md Khairuzzaman, TanjimHasin**, Matiur

$$
\text { Rahman Raju*** }
$$

Department of Civil Engineering, Faculty of Engineering, Universiti Putra Malaysia, 43400 UPM, Serdang, Malaysia.

**Department of Landscape Architect, Faculty of Design \& Architecture, Universiti Putra Malaysia, 43400 UPM, Serdang, Malaysia.

***Department of Civil Engineering, Faculty of Science \& Engineering, City University

Bangladesh, Dhaka-1215

*Email: zahidsabuz@gmail.com; Corresponding Author.

\begin{abstract}
Cement industries are responsible for huge amount of air pollution, which is harmful for the relevant workers health. According to a new questionnaire-based study, Bangladesh's cement industry has limited opportunities to follow green manufacturing practices. The aim of this paper is to investigate the situation of group wise environmental sustainability practices in Bangladesh, with the goal of assisting cement manufacturers in Bangladesh to improve their environmental sustainability practices in their manufacturing processes. In this paper, a comparison of cement manufacturers across Bangladesh's three major divisions was presented. It has been discovered that a large number of employees from these three departments are unaware of environmental concerns and sustainable industrial activities. Just $53 \%$ of the respondents are aware of the environmental concerns surrounding cement production and their customers are the primary sources of such knowledge. Furthermore, only $42 \%$ of respondents
\end{abstract}


used the ISO 14000 environmental quality control scheme, despite the fact that $53 \%$ of respondents used some kind of green manufacturing. Moreover, the causes for non-adoption as well as environmental factors affecting sustainable industrial practices have been identified and established. The lack of financial resources, lack of understanding and information about environmental issues, lack of demand from customers and stakeholders are the reasons why such practices have not been adopted. In order to follow green production methods, it is essential to use environmentally friendly cement materials, recycled-fiber packaging, biodegradable packaging and environmentally friendly waste management systems and technologies.

Key words: questionnaire; green manufacturing practices; inadequacy of financial incentives; Cement; environment sustainability.

\section{INTRODUCTION}

Over the last five years, Bangladesh's cement industry has experienced double-digit digital expansion. The country actually absorbs less than one fourth of $500 \mathrm{~kg}$ of cement per capita in the world in general. Sohel (2000) illustrated that Portland cement plays a critical role in the nation's overall development, as it is the key material in the construction industry. Banglapedia (2004) showed that building infrastructure projects have only increased the demand for cement's growth since the 1980s, particularly with the rise in urbanization, complex multifamily development, and suburban customers shifting preferences.

Iyawe et al. (2000) described that in developed nations, the cement factory area is cluttered with full of dust particles of different sizes and quantity, noise, and chemical pollutants. Marlowe and Mansfield (2002) mentioned that the key environmental concerns associated with cement manufacturing are air emissions (particulate matter, SOx, NOx), energy consumption, local pollution (noise, vibration, dust and visual impact), greenhouse gases, land use and biodiversity. When opposed to other industrial sectors, the sector has a higher number of 
accidents. There are also a variety of risks associated with the cement manufacturing operation such as exposure to dust and elevated temperatures, interaction with allergenic substances; and noise exposure, to name a few.

Lin and Ho (2011) assert that environmental problems are very imperative for sustainable development. The environment is very crucial in every part of the world. Kashiwagi (1996) demonstrated that the damage to the environment occurs through the loss of energy, the alteration of global climate and the contamination of the environment due to the removal of waste. Unfortunately, an array of environmental issues is a typical product of domestic and international companies. Therefore, corporate social responsibility and environmental sustainability have become the primary concerns of corporate operators under the surge of global sustainable growth championed by the United Nation (UN). Sustainability and social responsibility mean that the business must not only fulfill current needs, but also its abovementioned obligations to the future generations. The program focuses on raising volunteerism and sustainability awareness. Enterprises actively contribute to the economic development process and are expected to maintain or expand the productive use and completeness of resources. There is an interplay between the economy and the environment, such as problems associated with global warming. Since the ozone hole is an environmental challenge in several countries, international collaboration is necessary to address climate change in all countries. Therefore, business leadership does not seek to benefit blindly. To reach the anticipated level of global climate change, each country needs to refine and reinforce its commitment.

Due to the significant environmental damage, numerous manufacturing industries have gained the attention of researchers and industry leaders in the past few decades. Ratnasingam and Karl (2009) researched green manufacturing practices within the furniture industry and surveyed Malaysian furniture manufacturers to assess their preconceptions and attitudes towards sustainability. Based on the report, 54\% of cement industry companies follow green 
manufacturing practices. Other studies have shown that SMEs are not completely aware of environmental policies and are not interested in environmentally friendly goods and environmental management. Furthermore, Trandafilovic et al., (2017) demonstrated that education has a positive impact on people's understanding and respect for the environment, helps them to be more environmentally conscious and effective, and conserve resources. Furthermore, a review report on green technology in cement production has found that cement production sector has significantly improved over the years. Material and power can provide stewardship and environmental stewardship. Additionally, more strategies can leverage industries to improve environmental user-friendly technology. Besides, Rashid et al., (2019), Nguyen et al. (2018), Tang et al. (2018), Struwig et al. (2017) and Salimzadeh (2016) also considered environmental protection while conducting their studies.

Over the past decade, cement firms have made adjustments in response to the competition from various regions of the world. Programs such as total quality management (TQM), business process reengineering (BPR), supply chain management (SCM) and lean manufacturing (LM) have been described as the key to success in the cement industry (Ratnasingam, 2006). According to Parikka-Alhola (2008), in recent years, environmental-friendly or green manufacturing practices have emerged as an effective marketing criterion, and such practices are now employed as a strategic marketing strategy for cement industry. Bangladesh is a major producer and exporter of cement and is under pressure to follow green manufacturing practices (Ratnasingam et al., 2003). But the status of such practices in the industry is not well-known (Ratnasingam, 2006). Handfield et al. (1997) said that the marketplace must guide new, environmentally sustainable practices to be successful (Handfield et al., 1997, González-Benito \& González-Benito, 2008). The industry in Bangladesh lacks sufficient resources to follow green manufacturing practices. In this research, the status of green manufacturing practices in cement manufacturing in Bangladesh was evaluated and the key factors driving such initiatives 
were identified.

Among various researches, research related to the environment sustainability practice in cement industries in Bangladesh is still very rare and scarce. So, our research fulfills this limitation.

\section{METHOD}

Currently in Bangladesh there are 32 cement manufacturing companies of which 7 are currently listed and 4 are multinationals. $30 \mathrm{Mn}$ MT of cement per annum is being produced with local companies holding $80 \%$ of the market share due to their competitive advantage in price and quality. A survey of 200 respondents from 32 of the largest cement manufacturers in Bangladesh based on the listing of the Bangladesh Agro-Processors Association (BAPA) has been conducted utilizing structured-questionnaires. The development of the questionnaires has been done by consultation with industrial experts. The questionnaires were divided into four parts: (i) level of awareness of environmental issues, (ii) adoption of green manufacturing practices, (iii) reasons for non-adoption, and (iv) factors which contributing towards adoption or non-adoption of green manufacturing practices. The questionnaire had a total of 20 questions and the respondents, who were senior managers, had to mark the answers that reflected their company's position for all the statements, either based on a five-point scale known as Likert scale or ranking each statement by its importance as the senior managers are essential in decision making for the manufacturing practices. The questionnaire was tested earlier with ten manufacturers and corrected accordingly prior to the actual survey.

\section{RESULTS AND DISCUSSIONS}

\section{A. Level of awareness of environmental issues}

It has been observed that only $53 \%$ of the respondents are aware of the environmental issues related to cement producing and manufacturing and the main sources of such information are 
their customers. In fact, export-oriented manufacturers show significantly higher degrees of environmental-awareness in comparison to domestic-market manufacturers. The significant polluting constituents emitted to air are dust, nitrogen oxides (NOx) and sulphur dioxide (SO2). Carbon oxides, polychlorinated dibenzo-p-dioxins and dibenzofurans, total organic carbon, metals, hydrogen chloride and hydrogen fluoride are emitted as well. The type and quantity of air pollution depend on different parameters, e.g., inputs (the raw materials and fuels used) and the type of process applied.

\section{B. Adoption of environment sustainable manufacturing practices}

Only $42 \%$ of the respondents have adopted the ISO 14000 environmental quality management system, while $53 \%$ of the respondents practiced some green manufacturing practices. However, overall $47 \%$ of the respondents did not practice any green manufacturing practices. These scenarios are depicted in Figure 1 and Table 1.

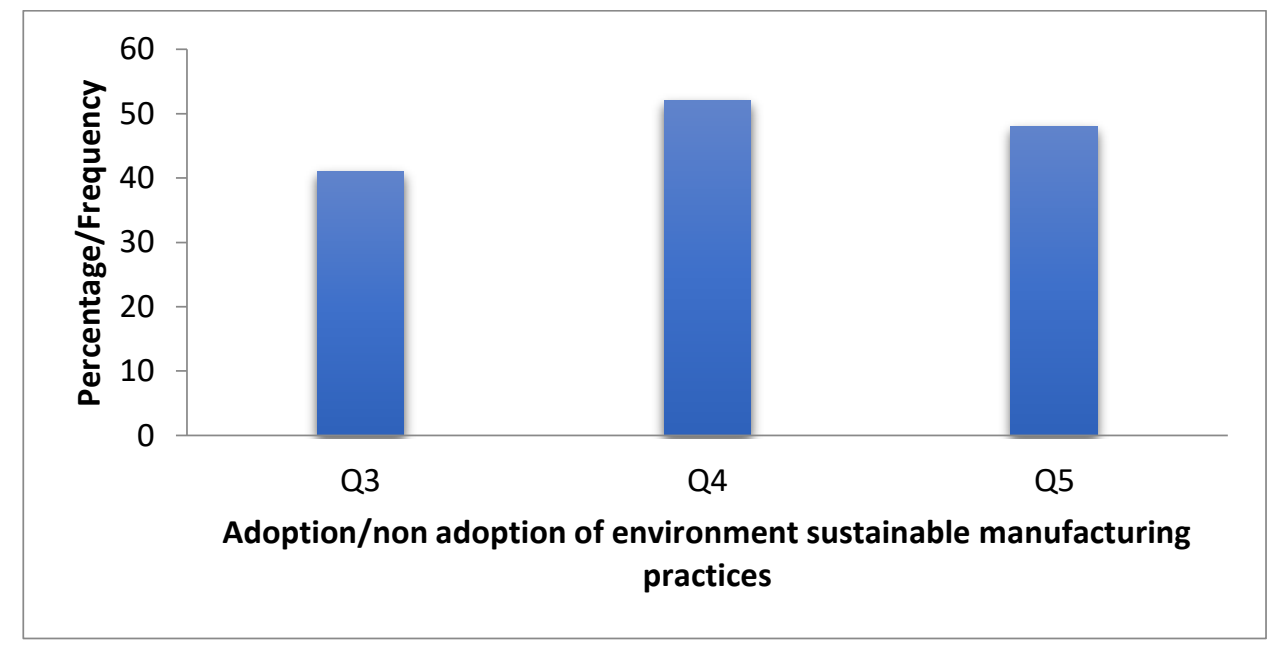

Figure 1 Adoption/non adoption of environment sustainable manufacturing practices

\section{Reasons for not adopting sustainable manufacturing practices}

Reasons of the manufacturer to avoid the adoption of environmentally sustainable manufacturing practices have been shown in Figure 2 and Table 1. Inadequacy of financial incentives has been detected as the most rated reason among the manufacturer from all regions 
for not adopting sustainable practice. $81 \%$ of the respondents have responded and answered that the inadequacy of financial incentives is the main reason for non-adoption among other reasons that was given. However, inadequacy of awareness regarding environmental issue, inadequacy of environmental knowledge, inadequate government pressure and less demand from customer and stakeholder have been detected as the contributing factors in the order of decreasing importance for the adoption of sustainable manufacturing practices among cement manufacturers in Bangladesh.

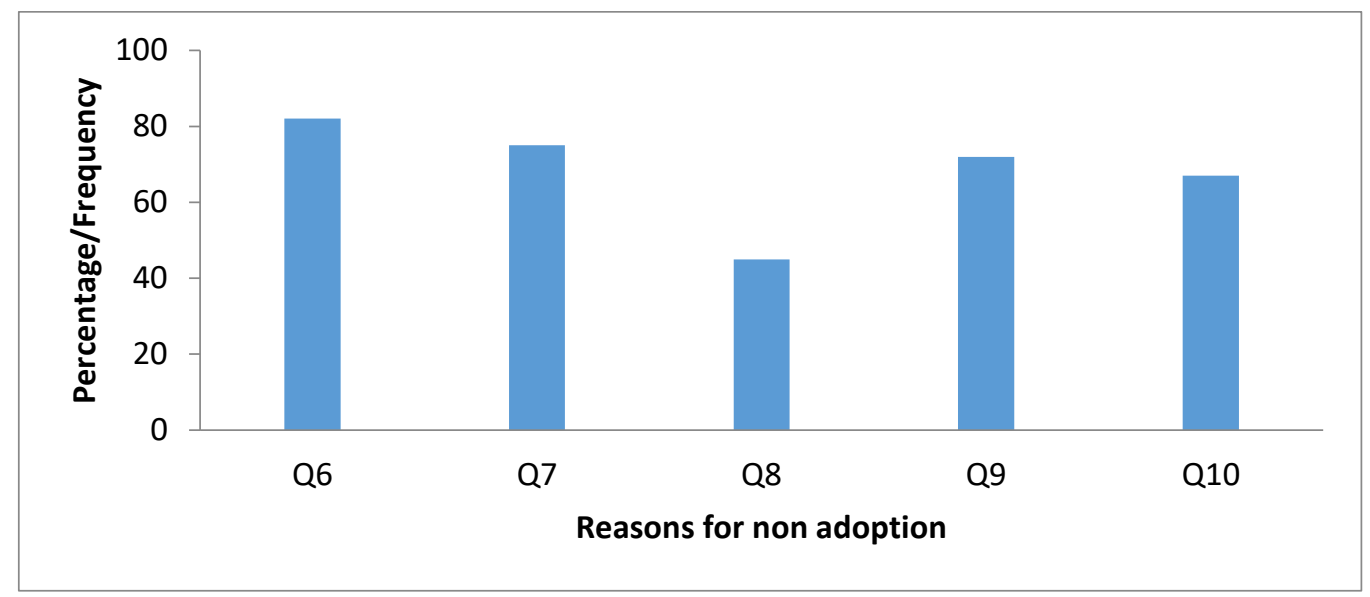

Figure 2 Reasons for not adoption

\section{Factors of environment sustainable manufacturing practices}

Seven potential factors for environmentally sustainable manufacturing practice have been considered in this survey. The utilization of recycled-fiber packaging is identified as the most rated factor which followed by the utilization of environmental affable manufacturing process. Meanwhile, the utilization of biodegradable packaging is identified as the lowest-rated factor followed by the environmental waste diminution which is clearly shown in Figure 3 and Table 1. 


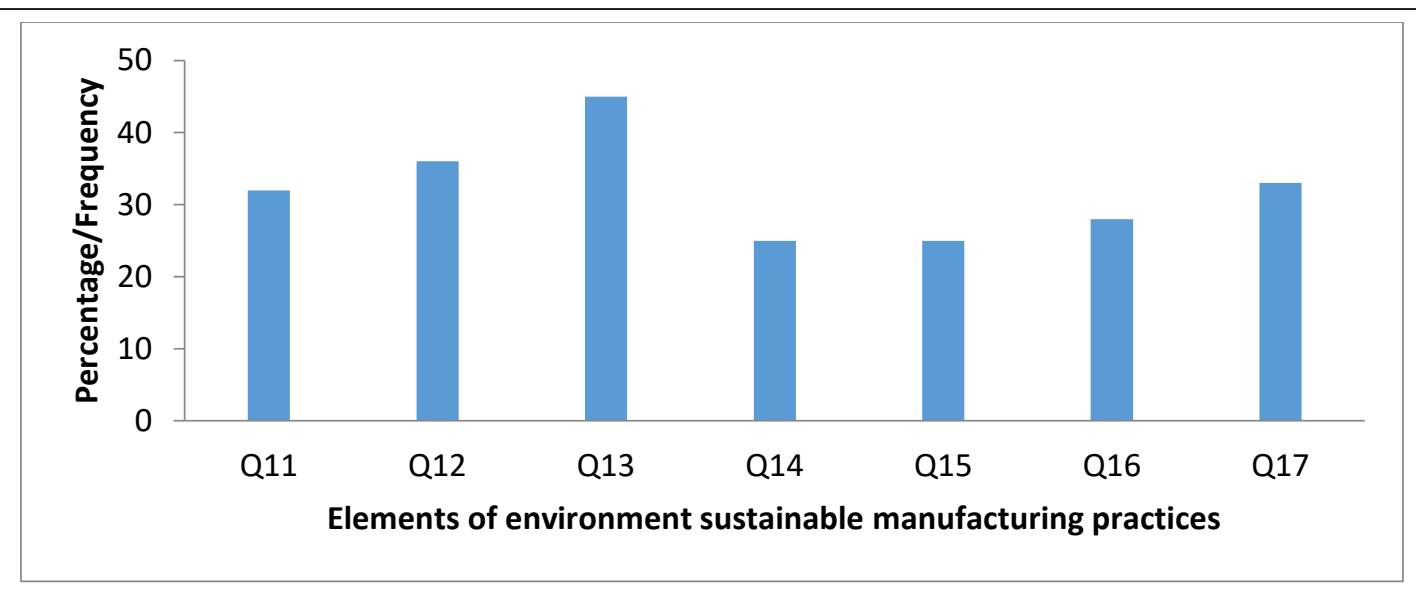

Figure 3 Elements of environment sustainable manufacturing Practices

Table 1 Environment sustainable manufacturing practices among cement industry

\begin{tabular}{|c|c|c|}
\hline Statement & Questions & Percentage $(\%)$ \\
\hline \multirow[b]{2}{*}{$\begin{array}{l}\text { Degree of awareness } \\
\text { regarding environmental } \\
\text { issues }\end{array}$} & $\begin{array}{l}\text { Q1 "Properly aware regarding the } \\
\text { basic environmental issue" }\end{array}$ & 55 \\
\hline & $\begin{array}{l}\text { Q2 "Completely aware regarding the } \\
\text { impact of cement manufacturing on } \\
\text { our environment" }\end{array}$ & 51 \\
\hline \multirow{3}{*}{$\begin{array}{l}\text { Adoption/non adoption of } \\
\text { environment sustainable } \\
\text { manufacturing practices }\end{array}$} & Q3 "Adoption of ISO 14000 system" & 42 \\
\hline & $\begin{array}{l}\text { Q4 "Adoption of environment } \\
\text { sustainable manufacturing practices" }\end{array}$ & 53 \\
\hline & $\begin{array}{c}\text { Q5 "Do not adopt environment } \\
\text { sustainable manufacturing practices" }\end{array}$ & 47 \\
\hline \multirow{5}{*}{ Reasons for not adoption } & $\begin{array}{l}\text { Q6 "Inadequacy of financial } \\
\text { incentives" }\end{array}$ & 81 \\
\hline & $\begin{array}{c}\text { Q7 "Inadequacy of environmental } \\
\text { knowledge" }\end{array}$ & 74 \\
\hline & $\begin{array}{l}\text { Q8 "Inadequacy of awareness } \\
\text { regarding environmental issue" }\end{array}$ & 46 \\
\hline & $\begin{array}{c}\text { Q9 "Inadequate pressure from } \\
\text { Government" }\end{array}$ & 71 \\
\hline & $\begin{array}{l}\text { Q10 "Less demand from customer } \\
\text { and stakeholder" }\end{array}$ & 66 \\
\hline
\end{tabular}




\begin{tabular}{ccc} 
& $\begin{array}{c}\text { Q11 "Utilization of certified cement } \\
\text { resources and materials" }\end{array}$ & 31 \\
\cline { 2 - 3 } & $\begin{array}{c}\text { Q12 "Utilization of environmental- } \\
\text { affable manufacturing process" }\end{array}$ & 37 \\
\cline { 2 - 3 } $\begin{array}{c}\text { Factors of environment } \\
\text { sustainable manufacturing } \\
\text { practices }\end{array}$ & $\begin{array}{c}\text { Q13 "Utilization of recycled-fiber } \\
\text { packaging" }\end{array}$ & 46 \\
\cline { 2 - 3 } & $\begin{array}{c}\text { Q14 "Utilization of biodegradable } \\
\text { packaging" }\end{array}$ & 24 \\
\cline { 2 - 3 } & $\begin{array}{c}\text { Q15 "Environmental waste } \\
\text { diminution" }\end{array}$ & 27 \\
\hline $\begin{array}{c}\text { Q16 "Utilization of environment } \\
\text { affable waste management system } \\
\text { for complete production process" }\end{array}$ & 34 \\
\hline $\begin{array}{c}\text { Q17 "Utilization of environmental- } \\
\text { affable technologies" }\end{array}$ & 26 \\
\hline
\end{tabular}

\section{CONCLUSION}

It has been determined that inadequacy of financial incentives, inadequacy of environmental knowledge and inadequate pressure from government are the major reasons for not adopting environment sustainable manufacturing practice. Thus, it is necessary to give proper environmental knowledge and awareness to the people. Government should impose adequate pressure and financial incentives for ensuring such practice. Moreover, recycled-fiber packaging, environmental affable cement materials, certified cements resources, environmental waste diminution, environment affable waste management system and technologies, biodegradable packaging should be strictly utilized and ensured for adopting environment sustainable green manufacturing practices.

\section{ACKNOWLEDGEMENTS}

The corresponding author would like to thank all the participants for their valuable responses. 


\section{REFERENCES}

Sohel, J.A. 2000. Locational Pattern of Cement Manufacturing firms in Khulna Division. Unpublished UndergraduateThesis, Urban and Rural Planning Discipline, Khulna University, Bangladesh, pp. 1-3.

Banglapedia, 2004. Cement industry. Asiatic Society of Bangladesh, Dhaka. URL: www.banglapedia.org

Iyawe, V.I.; Ebomoyi, M.I.E.; Chiwuzie, J.C. and Alakija, W. 2000. Some factors which may affect blood pressure in Nigerian cement factory workers. African Journal of Biomedical Research, 3: 117-121.

Marlowe, I. and Mansfield, D. 2002. Toward a sustainable cement industry: environment, health and safety performance improvement. World Business Council for Development, Geneva, Switzerland, 4 pp. URL: <www.wbcsdcement.org/ final_reports.asp>

Lin, C. Y., \& Ho, Y. H.2011. Determinants of green practice adoption for logistics companies in China. Journal of business ethics, 98(1), 67-83.

Kashiwagi, T.1996. Technological breakthrough and global cooperation. Global environmental security. Berlin: Springer, 25-69.

Ratnasingam, J., \& Wagner, K.2009. Green manufacturing practices among wooden furniture manufacturers in Malaysia. European Journal of Wood and Wood Products, 67(4), 485.

Fatoki, O.2018. Environmental sustainability practices of immigrant-owned small and medium enterprises in South Africa. European Review of Applied Sociology, 11(17), 27-43.

Trandafilović, I., Conić, V., \&Blagojević, A.2017. Impact of demographic factors on environmentally conscious purchase behavior. Економикапољопривреде, 64(4).

Rashid, M. H. U., Zobair, S. A. M., Shadek, M. J., Hoque, M. A., \& Ahmad, A. 2019. Factors Influencing Green Performance in Manufacturing Industries. International Journal of Financial Research, 10(6), 159-173.

Nguyen, M. H., Phan, A. C., \& Matsui, Y. 2018. Contribution of quality management practices to sustainability performance of Vietnamese firms. Sustainability, 10(2), 375. 
Tang, G., Chen, Y., Jiang, Y., Paille, P., \& Jia, J. 2018. Green human resource management practices: scale development and validity. Asia Pacific Journal of Human Resources, 56(1), $31-55$.

Struwig, F. M. W., \&Lillah, R. 2017. South African small and medium-sized enterprise owners' intention to implement an environmental management system. The Southern African Journal of Entrepreneurship and Small Business Management, 9(1), 1-8.

Salimzadeh, P. 2016. Sustainable Practices in Small and Medium Sized Enterprises in Regional Australia (Doctoral dissertation, Federation University Australia).

Ratnasingam, P. 2006. Perceived risks in supply chain management e-collaboration. Journal of Internet commerce, 5(4), 105-124.

Parikka-Alhola, K. 2008. Promoting environmentally sound furniture by green public procurement. Ecological economics, 68(1-2), 472-485.

Ratnasingam, J., \&Ioras, F. 2003. The sustainability of the Asian cement industry. HolzalsRohund Werkstoff, 61(3), 233-237.

Ratnasingam, J. 2006. Transforming the South East Asian Cement Industry. IramaPersada, Kuala Lumpur.

Handfield, R. B., Walton, S. V., Seegers, L. K., \& Melnyk, S. A. 19974. 'Green'value chain practices in the cement industry. Journal of Operations Management, 15(4), 293-315.

González-Benito, J., \& González-Benito, Ó. 2008. Operations management practices linked to the adoption of ISO 14001: An empirical analysis of Spanish manufacturers. International Journal of Production Economics, 113(1), 60-73. 